\title{
Nail-patella syndrome (Fong disease)
}

\author{
Scott A. Mooney • Johnny U. V. Monu
}

Received: 26 November 2009/Revised: 16 December 2009/Accepted: 5 January 2010 /Published online: 9 February 2010

(C) Springer-Verlag 2010

A 14-year-old boy presented to the orthopedic clinic for nonpainful elbow deformities. Knee radiographs demonstrated small patellae (Fig. 1). Elbow radiographs showed dislocation of the right radial head (Fig. 2). Pelvic radiograph was normal. Physical exam revealed bilateral absence of nails on the thumb and index fingers. Nail-patella syndrome was diagnosed.

Nail-patella syndrome (Fong disease, osteo-onychodysplasia) comprises four main components-nail dysplasia, hypoplastic or absent patellae, hypoplastic radial head and/or capitella (with or without dislocation), and iliac horns [1].

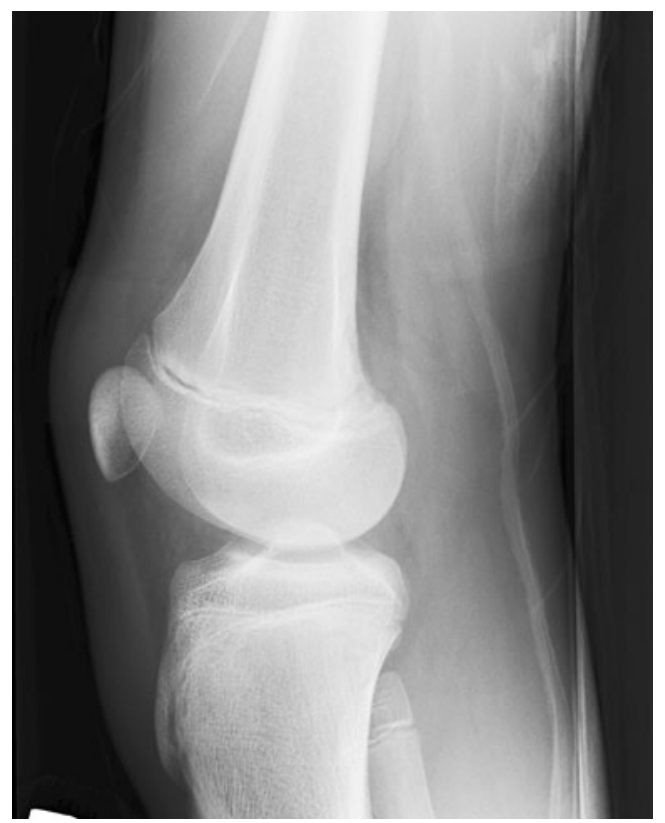

Fig. 1 Lateral view of the right knee

\section{S. A. Mooney • J. U. V. Monu ( $₫)$}

Department of Imaging Sciences, University of Rochester, 601 Elmwood Ave., Box 648, Rochester, NY 14642, USA e-mail: johnny_monu@urmc.rochester.edu

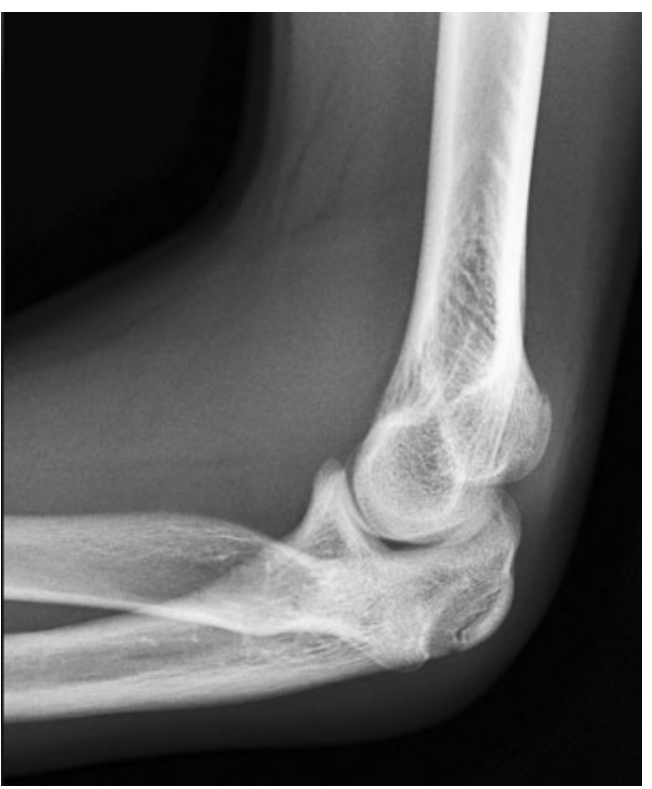

Fig. 2 Lateral view of the left elbow

Iliac horns, though pathognomonic, are present in only 70 $80 \%$ of cases. Complications include limited elbow extension and patellar subluxation. Thirty percent of cases are associated with glomerulonephritis or nephrotic syndrome. Radiographs and physical exam are diagnostic and can exclude other diagnoses with small patellae, including the small patella syndrome, Kuskokwim syndrome, and Coffin-Siris syndrome [2].

\section{References}

1. Itin PH, Eich G, Fistarol SK (2006) Missing creases of distal finger joints as a diagnostic clue of nail-patella syndrome. Dermatology 213:153-155

2. Azouz EM, Kozlowski K (1997) Small patella syndrome: a bone dysplasia to recognize and differentiate from the nail-patella syndrome. Pediatr Radiol 27:432-435 